\title{
CARACTERIZAÇÃO MORFOMÉTRICA DA BACIA HIDROGRÁFICA DO RIO SAPUCAIA COM APOIO DE SIG
}

\author{
Giovanna Matos Antonio $^{(a)}$, Alexandre Herculano de Souza Lima ${ }^{(b)}$, Renata Nunes \\ Azambuja $^{(\mathrm{c})}$, Ronaldo Missura ${ }^{(\mathrm{d})}$ \\ (a) Departamento de Geografia/Universidade Federal de Sergipe, giovannamatos.antonio@gmail.com \\ (b) Departamento de Geografia/Universidade Federal de Sergipe, dandefish@ hotmail.com \\ (c) Departamento de Geografia/Universidade Federal de Sergipe, pibidrenataufs@gmail.com \\ (d) Departamento de Geografia/Universidade Federal de Sergipe, ronaldomissura@gmail.com
}

\section{Eixo: GEOTECNOLOGIAS E MODELAGEM ESPACIAL EM GEOGRAFIA FÍSICA}

\begin{abstract}
RESUMO
O uso de sistemas de informações geográficas (SIG's) no auxilio de caracterizações de Bacias Hidrográficas se revela cada vez mais necessário e eficiente. Dentre as principais análises com que os SIG's operam estão as caracterizações morfométricas que podem auxiliar na gestão de recursos hídricos de bacias hidrográficas. A Bacia Costeira do Rio Sapucaia faz parte da nova divisão hidrográfica de Sergipe estabelecida em novembro de 2015, neste sentido ainda carece de análises voltadas ao seu estudo. O objetivo deste trabalho foi realizar uma caracterização morfométrica da Bacia Costeira do Rio Sapucaia com apoio de SIG's. Os principais resultados alcançados foram as mensurações de área $=119,02 \mathrm{Km}^{2}$; perímetro $62,91 \mathrm{Km}$; comprimento total dos canais $67,07 \mathrm{~km}$; comprimento do rio principal $21,14 \mathrm{Km}$; coeficiente de compacidade 1,61; comprimento da bacia $15,19 \mathrm{Km}$; fator de forma 0,51 ; densidade da bacia $0,56 \mathrm{Km} / \mathrm{Km}^{2}$.
\end{abstract}

Palavras-chave: hidrografia, morfometria, geoprocessamento.

\section{Introdução}

A bacia de drenagem ou bacia hidrográfica compreende um conjunto de canais de escoamento superficial interligados, sendo definida como uma área drenada por um rio ou por um sistema fluvial. Estes sistemas fluviais desempenham um papel relevante na geomorfologia, pois os canais fluviais constituem processos morfogenéticos.

As bacias hidrográficas são unidades de planejamento, análise e gestão ambiental de fundamental importância, as bacias costeiras, como a do Rio Sapucaia, são ainda mais importantes dada a interação entre o ambiente fluvial e marinho (CURTARELLI, 2009).

De acordo com FLORENZANO (2008) a morfometria é uma subdivisão da geomorfologia que se preocupa em estudar as informações quantitativas do relevo, e desta forma fornecer análises mais precisas para o planejamento de uso e ocupação territorial.

A partir da resolução n ${ }^{\circ}$ 25/2015 do Conselho Estadual de Recurso Hídricos o estado de Sergipe passa oficialmente adotar uma nova divisão hidrográfica, esta engloba duas novas bacias hidrográficas, a Bacia Costeira do Rio Sapucaia e Bacia Costeira do Caueira-Abaís (GOVERNO DE SERGIPE, 2015). 
Nesta perspectiva, o objetivo deste trabalho foi realizar uma caracterização morfométrica para Bacia do Rio Sapucaia com o intuito de oferecer subsídios informativos, uma vez que trata-se de uma temática ainda pouco discutida.

\section{Materiais e métodos}

A Bacia Hidrográfica do Rio Sapucaia é englobada totalmente pelo estado de Sergipe, situa-se entre os municípios de Pirambu e Japaratuba, sua foz esta localizada entre as desembocaduras dos rios Japaratuba e São Francisco, e com os seguintes pontos de extremidade territorial: $10^{\circ} 36^{\prime} 19^{\prime \prime} \mathrm{S}$ de latitude ao norte, $10^{\circ} 44^{\prime} 24^{\prime \prime} \mathrm{S}$ de latitude ao Sul, $36^{\circ} 54^{\prime} 8^{\prime \prime} \mathrm{O}$ de longitude ao oeste e $36^{\circ} 44^{\prime} 10 \mathrm{O}$ de longitude ao leste (Figura 1).

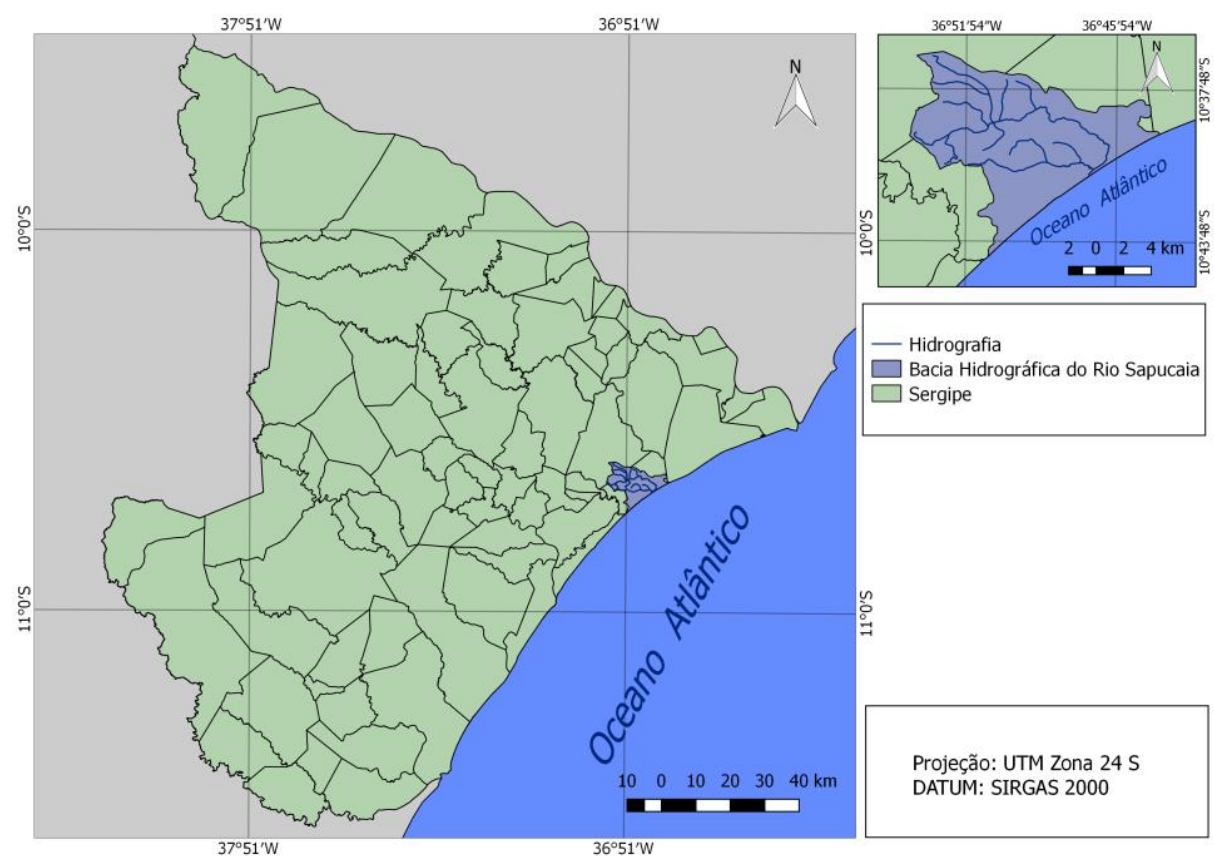

Figura 1. Localização da área de estudo. Fonte: SRH/SE (2016); IBGE (2015).

Os procedimentos metodológicos tiveram como ponto de partida o levantamento bibliográfico de livros, artigos e legislações que abordam o assunto em questão.

Em todas as caracterizações morfométricas da Bacia Hidrográfica do Rio Sapucaia, foi utilizado o software QGIS 2.8 e suas devidas extensões, o qual possibilita análises espaciais de maneira automatizada.

A estruturação do banco de dados georreferenciados compreendeu modelos digitais de elevação da Missão Topográfica Radar Shutter (SRTM), adquiridos através do sítio TOPODATA (Banco de Dados Geomorfológicos do Brasil) pertencente ao INPE. Utilizando-se da localização da bacia hidrográfica foi selecionada a imagem SRTM - 10S375ZN e delimitada e individualizada a bacia em 
foco. Também foi utilizado o arquivo vetorial referente aos limites da área da bacia hidrográfica, que foi adquirido através do Atlas 2013 da Secretaria de Recurso Hídricos de Sergipe.

As caracterizações físicas seguiram as fórmulas e conceitos contidos na obra de Villela e Mattos (1975).

Para obtenção dos valores de área e perímetro foram aplicadas funções do QQIS 2.8. Para obtenção dos dados da rede de drenagem além do QQIS 2.8 foi utilizado também o software SAGA GIS 2.1. Com os mesmos softwares foram ainda adquiridas informações morfométricas relativas ao comprimento total dos canais e do comprimento do rio principal.

Para obter-se as classes de declividade da bacia foi utilizado o QQIS 2.8, logo foi necessário a reprojeção do sistema de referência cartográfica de coordenadas geográficas, WGS 84, apresentado na imagem SRTM, para o correspondente sistema em coordenadas projetadas, WGS 84 zona 24 S. Em seguida o modelo digital de elevação foi processado para obtenção das classes de declividade segundo os parâmetros pré-estabelecidos pela EMBRAPA 1979. Os resultados relativos à declividade da bacia são apresentados na Figura 2.

O coeficiente de compacidade (Kc), segundo Villela e Mattos (1975), aumenta conforme o nível de irregularidade da forma da bacia, é a relação entre o perímetro da bacia e a circunferência de um circulo de área igual a da bacia, portanto varia de acordo com a forma da área da bacia. Quanto mais o coeficiente for próximo a um, maior será a susceptibilidade á enchentes. Para calculá-lo utilizou-se a Equação 1.

$\mathrm{Kc}=0,28 \mathrm{P} / \sqrt{A}$

Onde: $\mathrm{P}$ - perímetro; $\mathrm{A}$ - área da bacia.

O fator de forma relaciona forma da bacia com a de um retângulo. Bacias com baixo fator de forma são menos sujeitas a enchentes que outras de mesmo tamanho, contudo com fator de forma maior (Villela e Mattos, 1975). Para se obter o fator de forma utilizou-se a Equação 2.

$\mathrm{Kf}=\mathrm{A} / \mathrm{L}^{2}$

Onde: $\mathrm{Kf}$ - fator de forma; $\mathrm{L}$ - comprimento da bacia.

A densidade da bacia demonstra a maior ou menor velocidade com que a água deixa a bacia hidrográfica, desta forma é o índice que aponta o grau de desenvolvimento da rede de drenagem (Villela e Mattos, 1975). Para calculá-lo utilizou-se a Equação 3.

$\mathrm{Dd}=\mathrm{Lt} / \mathrm{A}$

Onde: $\mathrm{Dd}$ - densidade da drenagem; $\mathrm{Lt}$ - comprimento total de todos os canais. 


\section{Resultados e discussão}

Conforme os resultados obtidos, pôde-se constatar que o coeficiente de compacidade indica que na bacia do Rio Sapucaia não há grandes susceptibilidades a enchentes, pois apresenta um formato relativamente alongado. Esta informação entra em plena concordância ao ser cruzada com os valores do fator de forma (Tabela 1).

O relevo apresentou predominância das classes de declividade plana e suavemente ondulada. Em áreas mais restritas, principalmente as áreas associadas ao entalhamento dos rios, apresentaram declividades de classe ondulada e forte ondulada.

\begin{tabular}{l|c|c|}
\multirow{3}{*}{$\begin{array}{c}\text { Tabela 1. } \\
\text { caracterizações } \\
\text { Bacia }\end{array}$} & Área & $119,02 \mathrm{Km}^{2}$ \\
\cline { 2 - 3 } Rio Sapucaia. & Perímetro & $62,91 \mathrm{Km}$ \\
\cline { 2 - 3 } & Comprimento total dos canais & $67,07 \mathrm{Km}$ \\
\cline { 2 - 3 } & Comprimento do rio principal & $21,14 \mathrm{Km}$ \\
\cline { 2 - 3 } & Coeficiente de compacidade & 1,61 \\
\cline { 2 - 3 } & Comprimento da bacia & $15,19 \mathrm{Km}$ \\
\cline { 2 - 3 } & Fator de forma & 0,51 \\
\cline { 2 - 3 } & Densidade da Bacia & $0,56 \mathrm{Km} / \mathrm{Km}^{2}$ \\
\hline
\end{tabular}

Resultado das morfométricas da Hidrográfica do

A densidade de drenagem obtida foi de $0,56 \mathrm{~km} / \mathrm{km}^{2}$. De acordo Villela e Mattos (1975), esse valor varia entre $0,5 \mathrm{~km} / \mathrm{km}^{2}$ para bacias pouco drenadas a 3,5 ou mais nas bacias excepcionalmente bem drenadas, indicando, portanto, que a bacia estudada possui baixa capacidade de drenagem. 


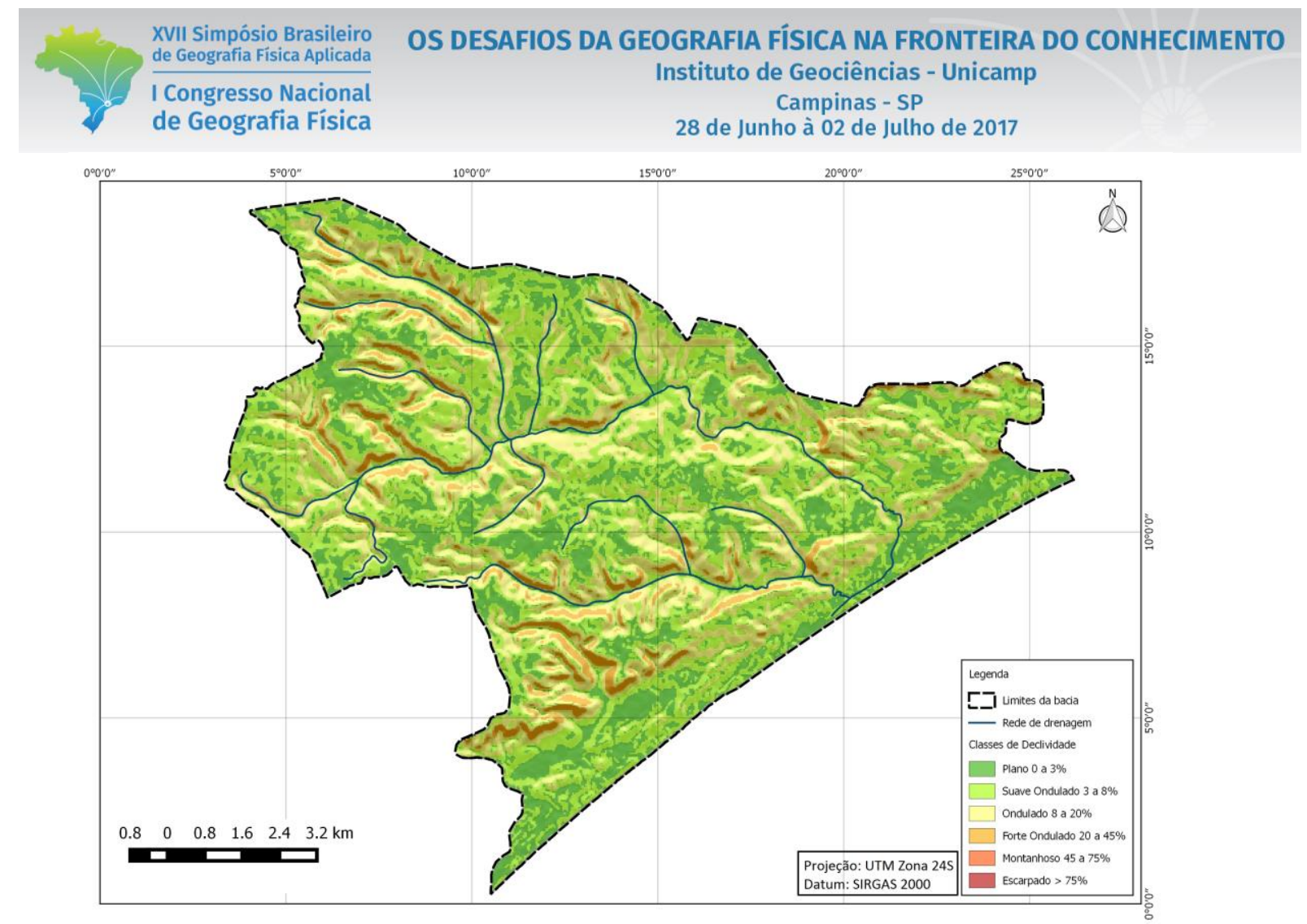

Figura 2. Classes de declividade da Bacia do Rio Sapucaia. Fonte: SRH/SE (2016); IBGE (2015); INPE (2016).

\section{Conclusão}

A aquisição das informações morfométricas da Bacia do Rio Sapucaia foram obtidas com sucesso, demonstrando que uso de SIG's por operarem com processamentos automatizados e precisos são uma opção viável para estudos desta natureza.

\section{Bibliografia}

BRASIL. Política Nacional dos Recursos Hídricos. Lei n. o 9.433, de 8 de janeiro de 1997.

URTARELLI, M. P. SIG aplicado à caracterização morfométrica de bacias hidrográficas - estudo de casoda bacia hidrográfica do rio Cubatão do Sul - Santa Catarina/Brasil. Anais do XIV Simpósio Brasileiro de Sensoriamento Remoto, Natal; INPE, 2009. 6 p.

CHRISTOFOLETTI, A. Geomorfologia. 2a ed. São Paulo: Edgard Blücher, 1980.

FLORENZANO, Tereza G. (org.). Geomorfologia: conceitos e tecnologias atuais. São Paulo: Oficina de Textos, 2008.

EMBRAPA. Serviço Nacional de Levantamento e Conservação de Solos (RIO DE JANEIRO, RJ). Súmula da 10. Reunião Técnica de Levantamento de Solos. Rio de Janeiro:1979. 83p. 
GOVERNO DE SERGIPE. Resolução $\mathbf{n}^{\mathbf{0}}$ 25, de novembro de 2015. Estabelece a divisão hidrográfica de Sergipe para implementação da Política Estadual de Recursos Hídricos e atuação do Sistema Estadual de Gerenciamento de Recursos Hídricos. 2015.

VILLELA, S.M.; MATTOS, A. Hidrologia aplicada. McGraw-Hill do Brasil, São Paulo, 1975, p.245. 